\title{
The Capital Asset Pricing Model And Fama-French Three Factor Model In An Emerging Market Environment
}

Adam Karp, North West University, South Africa

Gary van Vuuren, North West University, South Africa

\begin{abstract}
This paper tests the validity and accuracy of the Capital Asset Pricing Model and the Fama-French Three-Factor Model, by predicting the variation in excess portfolio returns on the Johannesburg Stock Exchange. Portfolios of stocks were constructed based on an adapted Fama-French (1993) approach, using a $3 \times 2$ annual sorting procedure, based on Size and Book-to-Market metrics respectively. The sample period spans six years, 2010 to 2015, and includes 46 companies listed on the JSE. The results indicate that both models perform relatively poorly because of inadequate market proxy measures, market liquidity restrictions, unpriced risk factors and volatility inherent in an emerging market environment. The Value Premium is found to explain a larger proportion of variation in excess returns than the Size Premium, and is more pronounced in portfolios with relatively higher book-to-market portfolios.
\end{abstract}

Keywords: Capital Asset Pricing Model; Value Premium; Three-Factor Model; Liquidity

\section{INTRODUCTION}

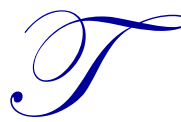

he notions of risk and return form the body of fundamental first principles of rational investing. Since the advent of modern financial systems, and the emergence of sophisticated markets, the question of how and what return premiums risk bearing assets should bear, in the presence of such risk, has been one which financiers and economists alike, have long been concerned. If the relationship between risk and return can be understood, and subsequently measured with suitable accuracy then the implications of such estimation are farreaching.

From a corporate investing perspective, asset-pricing models can generate evaluations of the cost of firm equity, ${ }^{1}$ a key component in the appraisal of capital budgeting as well as capital structure decisions. For individual investors, they serve as asset differentiation mechanisms; comparative tools which can be used to assess and decide on the composition of portfolio holdings, depending on investor preference.

One of the earliest asset pricing models of Sharpe (1964) and Litner (1965) developed using the foundational groundwork of Markowitz's (1952) mean-variance portfolio framework, led to the Capital Asset Pricing Model (henceforth, CAPM). The CAPM describes how the expected return on an asset or portfolio of assets is a linear function of the markets systematic risk component or market risk. Subsequent models, such as Arbitrage Pricing Theory introduced by Ross (1976) and later augmented by Chen, Roll and Ross (1986), introduced the notion of multivariate asset pricing models which estimated asset returns, in a manner which did not distinguish between the causality of macro and micro return predictors.

Fama and French (1993) extended the CAPM by showing that returns could be predicted by three factors, namely: Market, Size and Value, the outcome of which resulted in the formulation of the Fama-French Three Factor Model (henceforth, FF3FM). This finding has since been tested extensively with congruent findings occurring in many

${ }^{1}$ The rate of return paid to equity investors as risk compensation.

Copyright by author(s); $\underline{\text { CC-BY }}$ 
markets. While extensive studies have been applied to developed markets, specifically the US and Western Europe, the literature regarding the application of such models in emerging markets is sparse. This paper undertakes an empirical evaluation with the following objectives:

- To test the ability and validity of the CAPM and the FF3FM as predictive models in explaining excess stock returns on the Johannesburg Stock Exchange (Henceforth, JSE).

- To compare the performance of the CAPM relative to the FF3FM, to ascertain which model outperforms the other, with respect to explanatory power.

- If indeed there are significant size and value factors which affect stock returns, to determine which factor explains the larger proportion of the variation in stock returns.

This work adapts the methods used in Fama and French (1993) to accommodate South African data.

\subsection{A South African Perspective}

South Africa is a middle-income, emerging financial market. ${ }^{2}$ In 2013, South Africa was ranked the $19^{\text {th }}$ largest stock exchange in the world by market capitalisation ${ }^{3}$ and the largest exchange in Africa $(\approx 400$ listed companies (JSE, 2013)). While the JSE may be a relatively well-established exchange, there is a scarcity of literature with respect to asset pricing models applications and those involving the application of the FFTFM $(1993,1995)$. This work aims to add to the available literature.

The remainder of this article is structured as follows: Section 2 deals with the literature surrounding general asset pricing, with specific focus on the CAPM and FF3FM. Section 3 examines the data and methodology employed. Section 4 discusses the analysis and results, while Section 5 concludes and provides recommendations for further studies.

\subsection{The CAPM}

The CAPM, as presented in the works of Treynor (1961), Sharpe (1964), Lintner (1965) and Mossin (1966), relies on a series of stringent assumptions. A fundamental notion is that investors hold well-diversified portfolios, implying that idiosyncratic risk can be diversified away and the only risk for which investors are compensated is attributable to a systematic, non-diversifiable risk component (represented by the market). ${ }^{4}$ Other assumptions underlying the model are that investors:

1. Aim to maximise economic utilities (asset quantities are given and fixed),

2. Are rational and risk-averse,

3. Are broadly diversified across a range of investments,

4. Are price takers, i.e., they cannot influence prices,

5. Can lend and borrow unlimited amounts under the risk-free rate of interest,

6. Trade without transaction or taxation costs,

7. Deal with securities that are highly divisible (all assets are perfectly divisible and liquid),

8. Have homogeneous expectations, and

9. Assume all information is available at the same time to all investors. (Bodie, Kane and Marcus, 2008).

\footnotetext{
${ }^{2}$ One which has a low to middle per capita income.

${ }^{3}$ Around $\$ 1007 \mathrm{bn}$ at the start of 2014 .

${ }^{4}$ Idiosyncratic risk is the specific risk associated with a company or asset, while systematic risk refers to risk attributable to the market and its movements, which cannot be diversified away.

Copyright by author(s); $\underline{\text { CC-BY }}$ 


\subsection{A Brief Note on $\beta$}

Systematic risk is measured by the $\beta$ of a portfolio, defined as:

$$
\beta_{i}=\frac{\operatorname{Cov}\left(R_{i}, R_{m}\right)}{\operatorname{Var}\left(R_{m}\right)}
$$

where: $\operatorname{Cov}\left(R_{i}, R_{m}\right)=$ The covariance of asset/portfolio relative to the market, $\operatorname{Var}\left(R_{m}\right)=$ the variance of the market and $\beta_{i}=\beta$ of portfolio $i$. The expected return according to the CAPM, is then given as a linear function of the sum of the market risk-free rate of interest and the product of the $\beta$ and excess return, such that

$$
E\left(R_{i}\right)=R_{f}+\beta_{i}\left[E\left(R_{m}\right)-R_{f}\right]
$$

where: $E\left(R_{i}\right)=$ The expected return on asset/portfolio $i, R_{f}=$ The risk-free rate of interest, $\beta_{i}=$ The $\beta$ value of asset/ portfolio $i$ and $E\left(R_{m}\right)=$ The expected return on the market. (2) may be re-written:

$$
E\left(R_{i}-R_{f}\right)=\alpha+\beta_{i}\left[E\left(R_{m}\right)-R_{f}\right]+\epsilon_{i}
$$

where all the elements defined in (2) are the same in (3), $E\left(R_{i}-R_{f}\right)=$ the expected excess returns on portfolio $i$, $\alpha=$ intercept of the estimated regression line, $\beta_{i}\left[E\left(R_{m}\right)-R_{f}\right]=$ the excess return on the market premium and $\epsilon_{i}=$ random error component.

\subsection{The FF3FM}

The FF3FM served as a tool to address the shortfalls and complications associated with the CAPM. Fama and French $(1993,1995,1996)$ found that approximating returns using two other factors (size and value) in conjunction with the original market factor as presented by the CAPM, could significantly improve stock return estimation. The size of a firm is defined as the market capitalisation (henceforth, ME):

$$
M E=(\text { Share price }) \times(\text { number of outstanding shares in issue })
$$

The value premium of a firm - which is best represented by the Book-to-Market ratio (henceforth, BE/ME), reflects the firm's fundamental accounting value relative to current market value given by:

$$
\frac{B E}{M E}=\frac{(\text { Book Value of Equity })_{t-1}}{(\text { Market Value of equity })_{t}}
$$

Both the size and value premiums are captured in the model by engineering two portfolios called "Small minus Big" (SMB) and "High minus Low" (HML), in line with the methods used in Fama and French (1993, 1996) - and will be dealt with in further sections. The relationship between these three factors and the expected return on asset $i$ can be approximated as follows:

$$
E\left(R_{i}\right)=\alpha+b_{i} \cdot\left[E\left(R_{m}\right)\right]+s_{i} \cdot E(S M B)+h_{i} \cdot E(H M L)
$$

where $E\left(R_{i}\right)=$ expected return on asset/portfolio $i, R_{f}=$ risk-free rate, $E\left(R_{m}\right)=$ expected return on the market, $E(S M B)=$ expected return of the size factor, $E(H M L)=$ expected return on the value factor, $b, s, h=$ factor coefficients and $\alpha=$ regression intercept. (6) can be re-written to yield (7) which is used to run the multiple linear regressions for the FF3FM:

$$
E\left(R_{i}\right)-R_{f}=\alpha+b_{i} \cdot\left[E\left(R_{m}\right)-R_{f}\right]+s_{i} \cdot E(S M B)+h_{i} \cdot E(H M L)+\epsilon_{i}
$$


where all elements described previously are equivalent, $\alpha$ is the regression intercept and $\epsilon_{i}$ is the random error regression component.

\section{LITERATURE REVIEW}

Asset pricing has long been an area of considerable interest, with initial contributions dating back as early as the $18^{\text {th }}$ century (Bernoulli, 1738). ${ }^{5}$ The emergence of an integrated global community and the development and sophistication of financial markets have been the catalysts for its ever-increasing prominence. The uses of asset pricing models are vast: they serve as tools for management in the undertaking of capital budgeting decisions, pricing equity, as well as determining the cost of capital. These are all elements intrinsic to the operations of firms and investors.

The $20^{\text {th }}$ century saw the emergence of works, which have underpinned the fundamental ideas regarding meanvariance optimisation, equilibrium analysis, and investor preference. Most notable was the "mean-variance" model contribution of Markowitz (1952), forming the basis of Modern Portfolio Theory (MPT) - on which most subsequent asset pricing models are currently built. The model is a single period model, which assumes investors are risk adverse. Portfolio selection is undertaken at time $t-1$ and stochastic returns are determined at time $t$. The aim of the investor is to maximise expected return subject to their risk appetite.

\subsection{The Development of the CAPM}

Markowitz's (1952) work presents a direct and rudimentary foundation to the CAPM, developed during the 1960s, with collective contributions from Treynor (1961), Sharpe (1964), Lintner (1965) and Mossin (1966). The allure of the CAPM is that is described as offering powerful and intuitively pleasing predictions with respect to expected returnrisk relationships, in a rational equilibrium market (French, 2004).

Tests conducted on both versions of the model namely: The Sharpe-Lintner (Sharpe, 1964 and Lintner, 1965) and Black (1972) both arrive at the same conclusions. These inferences are two-fold. First, is the proposition that the covariance of asset returns with the market, relative to the risk or variance of the market $(\beta)$, is both adequate and sufficient in explaining the variation in asset expected returns; and secondly that the expected return- $\beta$ relationship is positive, and symbiotic in nature. Early cross-sectional tests and time-series regressions applied to both forms of the model, suggested that the relationship between asset returns and $\beta$ were found to be approximately linear. The addition of other explanatory variables also led to no significant explanatory improvement (perhaps because of the immature nature of financial markets at the time), resulting in a premature conclusion that the market proxy portfolio was indicative of a "stand-alone "indicator of risk.

\subsection{Limitations of the CAPM}

The CAPM pioneered the way in which assets are priced, however it is encumbered with several limitations. Firstly, the model makes a series of unrealistic assumptions and may be an inadequate representation of the behaviour of financial markets. Secondly, historical estimates of $\beta$ s are problematic as they have been found to vary considerably through time (Mullins, 1982). Roll (1977) criticised the CAPM by suggesting that it is impossible to observe a strictly diversified market portfolio, and a market index serving as a proxy for such a portfolio would inherently have predictive errors.

\subsection{The Size Effect}

The refutations with respect to the CAPM model stem primarily from empirical evidence. Simply put expected returns of assets were found not merely to be driven as a result of market risk, but instead a combination of additional risk factors. Basu (1977, 1983) and Banz (1981) for example, first documented what has come to be known as the "Size Effect," on US stock data. They showed that stocks with high earnings/price ratios, earned significantly higher returns

\footnotetext{
${ }^{5}$ Specifically, the St Petersburg's paper, published in 1738 which detailed and formed the basis of economic theory regarding risk aversion, risk premium and utility.
} 
than those with low earnings/price ratios. Moreover, returns for firms with relatively low ME were found to be significantly higher (return premium attached to small firms) than firms with relatively large market capitlisations.

The intuitive response in the defense of this finding points to the idea that small firms, in general, have higher $\beta \mathrm{s}$ than large firms. The resultant $\beta$ differences, however, was not significant enough to adequately explain the small-big capitalisation return disparity (Kampman, 2011).

\subsection{Book-to-Market/Value Effect}

The Book-to-market effect or value effect was first documented by Reid, Rosenberg and Lanstein (1985) using US data, and later confirmed by Davis (1994) (also using US data), Lakonishok (1991) (Japanese data) and Fama and French (1996) using international market data. The effect postulates that that there exists a positive relationship between a firm's book-to-market ratio (BE/ME) and forecasted returns, and a return premium should be given to stocks with relatively higher book-to-market ratios. ${ }^{6}$ Fama and French (1992), showed that a cross-sectional regression of book-to-market ratios on realised returns yielded a positive coefficient that was approximately six standard deviations different from zero.

While recent literature has uncovered various other variables which affect the variability of stock returns such as: profitability, liquidity and idiosyncratic volatility - none appear to feature more prominantely in the litreture than the Size and Value effects (Drew, Naughton, \& Veeraraghavan, 2004). Treatment of other variables will not be dealt with explicitly here, as they fall outside the scope of this paper.

\subsection{The FF3FM}

The above-mentioned considerations suggest that the single factor CAPM is not entirely suitable for explaining the relationship between risk and return. While many models have emerged as a result of the persistent issues associated with CAPM, none are perhaps used as extensively as the FF3FM (1993). The model postulates that the cross-sectional variation in the expected returns of an asset is a function not only of the market premium, but instead, a combination of three priced factors. ${ }^{7}$

Fama and French (1993) conducted a study which analysed a total of 25 US based equity portfolios (spanning a period from July 1963 through to December 1991) and found that the cross-section of average return on US stocks could be explained overwhelmingly by three factors namely: excess market returns, a book-to-market or value factor, and a size factor.

Fama and French (1993) found that two classes of stocks tended to outperform the market. The first being smallcapped stocks and the second being "value" stocks (stocks with high book-to-market ratios). ${ }^{8}$ As a result, the FF3FM, models the Size and Value effects as risk premia - i.e. as compensation to the investor for holding less profitable, more volatile stocks.

This logic has not been without contention, however, opponents such as Lakonishok, Shleifer, \& Vishny (1994) and La Porta (1996), advocate a behavioural explanation in the belief that the Book-to-Market Effect is a result of investors extrapolating past portfolio performance too far forward into the future. This would in turn lead to the underpricing of value stocks and overpricing of growth stocks, rather than being as a result of compensation for risk bearing investors (Djajadikerta \& Nartea, 2005).

Daniel and Titman (1997) provide a characteristic explanation in which they argue that the Book-to-Market Effect is a manifestation of particular characteristics of firms, which are intrinsic to investor preferences. Investors were found

\footnotetext{
${ }^{6}$ That is: BE ratio = Book Value of Equity/Market Value of Equity appeared to resonate strongly with expected returns.

${ }^{7}$ Note: Factors and Premiums are used interchangeably throughout the paper, as is the Book-to-market and Value factors.

${ }^{8}$ Low BE/ME ratio stocks are defined as "growth" stocks and are characterised by increases in capital value rather than high income/profit yielders - they tend to achieve higher growth rates than the market. Value stocks tend to trade at prices which are low relative to its fundamentals and are considered undervalued by the market.
}

Copyright by author(s); $\underline{\mathrm{CC}-\mathrm{BY}}$ 
to have a higher propensity to hold "growth" stocks versus "value" stocks. In response to this critique Fama, French and Davies (2000) applied thee FF3FM model to an extended data set (1929-1997) and argued that the results of Daniel and Titman's (1997) report were period-specific, leading to spurious conclusions, and not applicable to other time periods.

Another concern surrounding The FF3FM was the notion of 'data mining'. Fama and French (1996) respond to this by applying the Three Factor Model to other sets of data, spanning different periods, and show that the same relation between the variables is observed.

It is important to note that the FF3FM (1993) was developed and tested primarily on US data, the majority of stocks on which are comprised of industrially intensive industries, and thus, the resultant conclusions may only be relevant to markets with a particular set of characteristics.

\subsection{Evidence from Developed Markets}

Griffin (2002), using monthly data from 1981 to 1995, tested the FF3FM in the United Kingdom, Canada and Japan and reported that the Size and Value premiums do indeed contribute significantly to the explanatory power of the model. Lam (2002), using data for 100 Stock Exchange of Hong Kong (SEHK) listed stocks also reported results to support Fama and French's findings. Australian studies attributed to Faff (2001) and Gaunt (2004) report that the statistical significance, and parameter magnitudes, are comparable with Fama and French (1993, 1995) to a partial degree - noting a significant size effect with little evidence to suggest a significant book-to-market effect. This is in contrast to Kassimatis's (2008) findings, which concluded that the FF3FM did not provide convincing evidence. More recently, Gregory and Michou (2009) applied the three-factor model on the UK stock market, in which the Size and Value factors were found to vary through time, and overall results were found to be similar, yet more explanatory compared with those of the CAPM.

\subsection{Evidence from Emerging Markets}

Silva (2006) found that the Brazilian market $\beta$ was found to be statistically significant, and the explanatory power of the model improved with the addition of the Size and BE/ME factors. Pasaribu (2009) found similar results when the model was applied to the Indonesian stock market. Overwhelmingly, most the literature on emerging markets point to the idea that returns on individual stocks tend to be an increasing function of the book/market ratio and decreasing function of its “size" (Fama \& French, 1998; Drew \& Veeraghaven, 2001; Lockwood, Rodriquez, Goldreyer, \& Barry, 2002).

\subsection{Evidence from South Africa}

There exists a sparse set of South African literature with respect to the application of the FF3FM on the JSE. Valery (2015) mentions that since South Africa is an emerging, and relatively "immature" market, the lack of academic interest in the general African financial markets; and more precisely the lack of consistent and reliable data could be reasons to justify this. Auret and Sinclair (2006), were among the first to apply the Three-Factor Model to the JSE and in their study, monthly data for stocks from all sectors of the JSE were assembled from 1990 to 2000 . Return data were obtained, adjusted for dividends and capital events and a thin trading filter was used to ensure that the trading volume of each share exceeded at least one per period. Univariate and multivariate regressions were then undertaken to test the significance of the explanatory variables with respect to estimating excess stock returns. As per Fama and French (1992), a significant positive relationship was found between the BE/ME factor and expected stock returns. In addition, when the Value factor was applied to the model of van Rensburg and Robertson (2003), it almost entirely subsumed the Size factor (as evidenced in terms of explanatory power). 
Basiewicz and Auret (2010) used data on every listed share in the JSE from December 1989 to July $2005 .{ }^{9}$ Firms with missing accounting data, financial statements denominated in foreign currency, and missing market data were omitted from the analysis - to reduce potential bias of the results. ${ }^{10}$ The proxy used for the risk-free rate was the three-month T-bill rate. This contrasts with one-month treasury bills available in the US and other developed markets - however, the three-month instrument is the most liquid risk-free proxy South Africa has. Utilising time series regressions, it was found that the FF3FM was able to account, signficantly, for the Value effect. However, the BE/ME factor loses statistical power in predicting pricing errors once the Size factor is included as an explanatory variable.

A recurring issue for the successful application of the FF3FM in South Africa, is liquidity. Evidence suggests that the FF3FM does not perform well in illiquid markets as this may result in biases in estimated returns through the mismeasurement of risk parameters (Valery, 2015). Since the largest capped company in South Africa is a small cap firm in the US, this raises concern for potential modeling issues. Hearn and Piesse (2013) addressed the liquidity issue by augmenting the FF3FM model to include a priced liquidity factor in both South Africa and Kenya (Nairobi Stock Exchange). Monthly data were collected from 1991 to 2007 and converted into USD to remove volatility effects of currency premiums when calculating excess returns. Stock price returns were computed on a daily basis and then divided by daily trading volumes. Daily trading volumes and share price levels were used to construct liquidity factors. An average liquidity factor was computed monthly for each stock. Stock illiquidity was measured and defined as the ratio of the absolute value of the percentage price change of a stock per US \$ of equity trading volume (Hearn \& Piesse, 2013). The liquidity factor was found to significantly improve portfolio return estimation. The study showed that illiquidity was both a consistent and a priced characteristic in South Africa and Kenya. While the size factor was found to be as important a component in emerging markets as it is in developed markets, the primary risk component prevalent in emerging markets is Illiquidity (Valery, 2015).

Tony-Okeke (2015) supports this finding, by showing that a Fama-French liquidity adjusted-four factor model performs significantly better in explaining expected returns. Moreover, Tony-Okeke (2015) concludes that the Value (BE/ME) factor is insignificant on the JSE, and that in contrast to popular findings, large stocks outperformed small stocks, with liquid stocks outperforming illiquid ones.

The literature indicates that some results were consistent with the findings of Fama and French $(1993,1996)$, and others not. The resultant findings of Fama andFrench (1993) are very much country specific. Differing market characteristics, the extent of market sophistication, risk exposures and industry specific market weightings are all issues which may affect the models outcomes. The most persistent problem with previous studies on the JSE are associated with illiquidity. To address this and to avoid liquidity adjustments, this work explored the top 50 companies (by market capitalisation and trading volume) on the JSE. The data have been adapted to rid them of potential bias in line with suggestions of Valery (2015) and Basiewicz \& Auret (2010). The time period of the model encapsulates an expansionary phase of the South African business cycle $(2010$ - 2015) so as to avoid robustness issues.

\section{DATA AND METHODOLOGY}

The time period under consideration extended from January 2010 to January 2015. The reason for this choice was firstly to address the issue of potential estimate bias. Ceteris paribus, the longer the time horizon of estimation, the higher the probability of the $\beta$ values of the factors changing over the period (Bartholdy and Peare, 2005). Secondly, the Fama and French model (1993) has been shown to perform unsatisfactorily in periods of downturn or economic contraction. This paper assesses the FF3FM in a period of positive average economic growth in South Africa. Thirdly, since the FF3FM has been shown to lack robustness during downturn in developed markets, an emerging market environment (South Africa) which tends to exhibit greater volatility then developed markets would most likely exacerbate the issue.

\footnotetext{
${ }^{9}$ The sample period spanned June 1992 to July 2005 and included 894 companies; previous data were collected in order to collect prior accounting data which was used to estimate loadings.

${ }^{10}$ Denominations in foreign currency imply a risk to the real market value of firm operations.

Copyright by author(s); $\underline{\mathrm{CC}-\mathrm{BY}}$ 
Initially, all relevant data were collected on 53 of the most liquid JSE shares (rebalanced annually), over a period of five years ( 40 of which constituted the components of the JSE Top 40 index). This list included a variety of industries which would ensure that the portfolios would be well diversified.

\subsection{The Market Index}

Motivating the choice of a market index proved difficult. The FTSE/JSE All-Share index which represents $99 \%$ of the JSE's ME and is constructed using 164 companies was used as a proxy for the market index (JSE, 2013). The FTSE/JSE Top 40 Index thus provides a more appropriate proxy for the data pool. After data adjustments were made, the total number of firms used in the study stood at 46 . Thus, the overwhelming majority of the firms in the sample were members of the Top 40 in each of the respective years. Moreover, the JSE Board make use of a liquidity screening process in which companies are filtered from the Index, should they be too illiquid. Although the index is comprised of 40 companies, this composition represents over $85 \%$ of the total ME of JSE listed companies.

\subsection{The Risk-Free Rate}

Conventional studies in developed markets such as the US and Europe make use of one month T-bills or government bond equivalents as the risk-free approximation. For South Africa, the shortest term risk-free instrument is the 3month Treasury-Bill, and is the rate used in the study. Annualised rates were retrieved from the South African Reserve Bank (SARB) after which average monthly rates were calculated using $R_{f^{\prime}}=\sqrt[12]{1+R_{f}}-1$ where $R_{f^{\prime}}=$ the monthly percentage rate of interest (\%) and $R_{f}=$ the annual interest rate.

\subsection{Value of Book and Market Equity}

An important component for computing risk factors for the FF3FM involves the use of BE/ME ratios.

\section{A Brief Comment on Liquidity}

To address the problem of liquidity, the study employed the use of the Top 40 Index as a proxy for the market, a method in line with Valery (2015). Another method employed by Basiewicz and Auret (2010), who applied the three factor model to 200 companies in the JSE, involved setting restrictions on price and liquidity. In that particular case, stocks which had share turnovers below $0.001^{11}$ were excluded. For this study the sample size of firms was considered too small for a meaningful adjustment of that nature to occur: future work could employ a larger data sample.

\subsection{Data Adjustment Prior to Portfolio Construction}

The original data sample comprised 53 companies. Companies associated with missing or incomplete data were removed from the sample so as to prevent any potential bias when the portfolios were formed, and the respective regressions run. Any companies falling on a median, upper or lower quartile split, when partitioning companies into ME sizes, were excluded. Companies which issued financial statements denominated in foreign currency were also excluded (Basiewicz \& Auret, 2010). Listed companies on the JSE are quoted in rands (ZAR), as is the calculated yield on the market index and risk free rate. An exchange rate conversion to address this would be both difficult constant rebalancing would need to occur to reflect daily movements - and inaccurate; this would cause a loss of real value for companies. After adjustments, the final database comprised 46 stocks.

\footnotetext{
${ }^{11}$ Share turnover as a proxy for share liquidity is computed by dividing the aggregate shares traded over a set period by the average number shares outstanding for the specified period. The higher the value of the ratio, the more liquid is the share of the company or portfolio.
}

Copyright by author(s); $\underline{\mathrm{CC}-\mathrm{BY}}$

The Clute Institute 


\subsection{Portfolio Construction}

\section{Partitioning}

To create portfolios which track the Size and Value factors, the sample of firms were sorted annually by the ME and BE/ME ratio similar to Fama and French (1993). For the size consideration, firms were stratified each year by a median value and are classified as either "Big" (henceforth, B), for companies lying above the median, or "Small" (henceforth, $\mathrm{S}$ ), for companies lying below the median. Companies which fall on the median are excluded from the analysis so as to avoid bias. Similarly, firms are sorted annually into three other sub-groups based on their book-to-market ratios. The low group (L) contains firms with the lowest $30 \% \mathrm{BE} / \mathrm{ME}$ ratios, the medium ratio group with the middle $40 \%$ (M), and a large group with the highest $30 \%(\mathrm{H})-$ see Table 2 .

Table 2. Summary of the general partitioning procedure of portfolios based on percentile split and on Size and Book-to-Market ratios.

\begin{tabular}{c|c|c|c}
\hline \multirow{2}{*}{ Size } & & Book to market & Below 30\% \\
\hline Above 50\% & Above 70\% & Between 30\% and 70\% & Big/Low (B/L) \\
\hline Below 50\% & Big/High $(\mathrm{B} / \mathrm{H})$ & Big/Medium $(\mathrm{B} / \mathrm{M})$ & Small/Low $(\mathrm{S} / \mathrm{L})$ \\
\hline
\end{tabular}

High ratio firms are often referred to as value firms as they appear to provide an investor with good value, since they sell at low multiples of their respective book values (Bodie, Kane \& Marcus, 2008). The portfolio intersections of the two size and three book-to-market categories are then found, for each respective year, such that six portfolios are formed: $\mathrm{S} / \mathrm{L}, \mathrm{S} / \mathrm{M}, \mathrm{S} / \mathrm{H}, \mathrm{B} / \mathrm{L}, \mathrm{B} / \mathrm{M}$, and $\mathrm{B} / \mathrm{H}^{12}$ and their monthly returns computed. Table 3 depicts the partitioning procedure on a value determined basis, while Figure 1 shows the number of companies in each portfolio group from 2010 to 2015.

Table 3. Value specific partitioning based on the sample data used in the study, indicating threshold category values.

\begin{tabular}{|c|c|c|c|c|c|c|c|c|}
\hline Partitioning cutoffs & $\begin{array}{c}\text { Cutoff } \\
\text { proportion }\end{array}$ & 2010 & 2011 & 2012 & 2013 & 2014 & 2015 & $\begin{array}{c}\text { Period } \\
\text { average }\end{array}$ \\
\hline Market cap (ZAR bn) & $50 \%$ & 42115 & 40372 & 58961 & 61874 & 75542 & 84073 & 60490 \\
\hline $\mathrm{BE} / \mathrm{ME}$ & $30 \%$ & 0.260 & 0.327 & 0.284 & 0.255 & 0.261 & 0.250 & 0.273 \\
\hline $\mathrm{BE} / \mathrm{ME}$ & $70 \%$ & 0.580 & 0.710 & 0.622 & 0.651 & 0.675 & 0.812 & 0.675 \\
\hline
\end{tabular}

\footnotetext{
${ }^{12}$ As a matter of clarity, S/L corresponds to the portfolio of stocks which is classified as both small and having a low book-to-market ratio. Similarly, $\mathrm{B} / \mathrm{H}$ corresponds to the portfolio which is big in size and has a high book-to-market ratio etc.
} 
Figure 1. Distribution of the number of companies in each portfolio from 2010 to 2015, rebalanced annually.

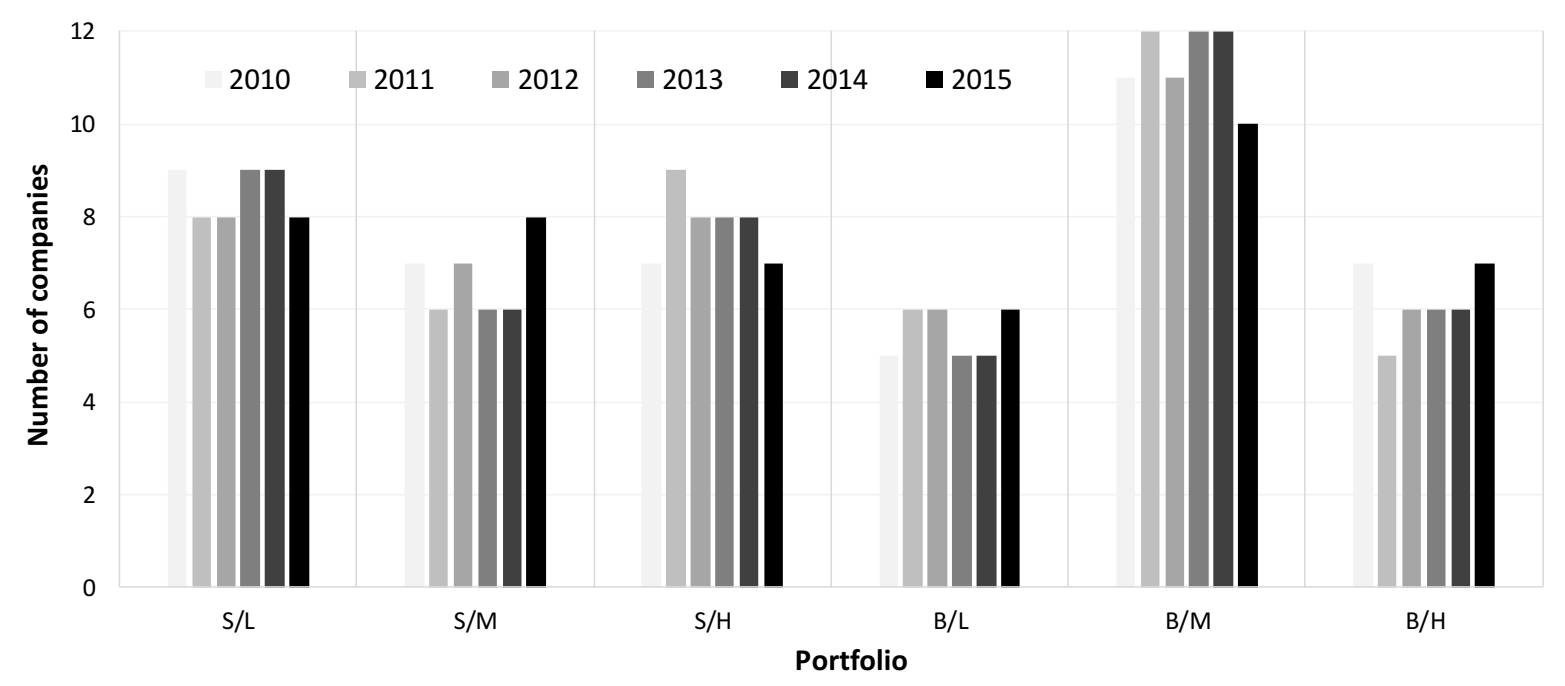

Explanatory Variables

$\underline{\text { SMB Factor }}$

Following the formation of the intersection portfolios, the Size premium, SMB, was constructed and is defined as the resultant difference of returns between small and large firms. More precisely, that is the difference in monthly returns between the sum of an equally weighted long position in the Small sized portfolios and the sum of a short, equally weighted position in the low Big sized groups (Bodie, Kane \& Marcus, 2008). Mathematically this can be expressed as:

$$
S M B=\frac{1}{3}\left(\frac{S}{L}+\frac{S}{M}+\frac{S}{H}\right)-\frac{1}{3}\left(\frac{B}{L}+\frac{B}{M}+\frac{B}{H}\right)
$$

where: $S / L, S / M, S / H, B / L, B / M$, and $B / H=$ the intersection of each respective portfolio formed on size and bookto-market values.

\section{$\underline{\text { HML Factor }}$}

The book-to-market effect was captured by calculating the difference in the monthly returns between firms with relatively high BE/ME ratios, and firms with relatively low BE/ME ratios. Medium portfolios were excluded from the calculation, as Fama and French (1993) note that HML variable performs best when defined in the fashion employed. The high minus low (HML) factor can be understood as the difference in monthly returns between an equally weighted long position in high $\mathrm{BE} / \mathrm{ME}$ ratio portfolios coupled with an equally weighted short position in low BE/ME portfolios.

$$
H M L=\frac{1}{2}\left(\frac{S}{H}+\frac{B}{H}\right)-\frac{1}{2}\left(\frac{S}{L}+\frac{B}{L}\right)
$$

where: $H M L=$ the high - low or "value" factor, $S / H=$ the monthly excess return on the small-high portfolio; $\mathrm{B} / \mathrm{H}=$ the big-high portfolio and $S / L=$ the small-low portfolio; $\mathrm{B} / \mathrm{L}=$ the big-low portfolio.

\subsection{Explanatory Variables in the Regression}

Excess returns $\left(R_{i}-R_{f}\right)$ on each of the six portfolios are used as dependent variables in the subsequent regression. Fama and French (1993) used more portfolios (25) due to their higher number of classification fields. Such partitioning Copyright by author(s); $\underline{\text { CC-BY }}$ 
was deemed inappropriate because the sample size was far smaller and thus avoided having small numbers of stocks in each portfolio.

\subsection{Statistical Techniques}

Descriptive Statistics

The first four moments of each excess return portfolio are considered (monthly and annually) to provide a general characteristics profile for the different stock portfolios.

\section{Moment Scaling}

When comparing dissimilar metrics, different scaling procedure applications are required to address the time-varying dynamics of return distributions. Correct scaling is imperative in order to ensure that metrics are compared on an equal footing (Gabrielsen, Kirchner, Liu \& Zagaglia, 2012). Table 4 summarises the scaling requirement from a monthly to $n$-period value, applied to the data.

Table 4. Monthly to an $n$-period value scaling formulae summary, employed for the first four moments of the return distributions. ${ }^{13}$

\begin{tabular}{l|c|c|c|c}
\hline \multicolumn{1}{c|}{ MOMENT SCALING } & Mean & Standard deviation & Skewness & Kurtosis \\
\hline Monthly value & $\mu_{m}(\%)$ & $m(\%)$ & $S_{m}$ & $K_{m}$ \\
\hline$n$-period scaling & $\left(1+\mu_{m}\right)^{n}-1$ & $\sigma_{m} \times \sqrt{n}$ & $\frac{S_{m}}{\sqrt{n}}$ & $\frac{K_{m}+3 \cdot(n-1)}{n}$ \\
\hline
\end{tabular}

Time-Series Regression and Backward Elimination

Time-series regressions were applied to the various portfolios.

Paired Sample T tests and the P-Value Approach

Partial $t$ - tests were conducted on each portfolio and their respective factors coefficients to test for significance at the $5 \%$ level.

\section{Durbin Watson Test Statistic}

Auto-correlation amongst residuals could underestimate the true variance of the regression model and may lead to the rejection of the null hypotheses when it is in fact true (type 1 error). To address the potential issue of auto-correlation amongst residuals, the Durbin Watson test statistic is used. The following hypothesis is tested using a critical value comparison approach:

$\boldsymbol{H}_{\mathbf{0}}: \rho=0$ (there exists no auto- correlation present amongst the residuals)

$\boldsymbol{H}_{1}: \rho \neq 0$ (auto- correlation amongst the residuals exists)

The test statistic has been computed in excel for each portfolio using:

$$
d=\frac{\sum_{t=2}^{T}\left(e_{t}-e_{t-1}\right)^{2}}{\sum_{t=1}^{N} e_{t}^{2}}
$$

\footnotetext{
${ }^{13} \mu=$ the mean, $\sigma=$ the standard deviation, $S=$ skewness,$K=$ kurtosis.
} 
where: $e_{t}=y_{t}-\hat{y}_{t}$; and $y_{t}$ and $\hat{y}_{\mathrm{t}}$ are the observed and predicted values of the response variable at time $\mathrm{t}$ respectively and $d=$ The Durbin Watson test statistic.

Augmented Dickey Fuller Test (ADF) Result

The Augmented Dickey Fuller test was also run to test for stationarity. The ADF test, tests the null hypothesis of whether a unit root exists in the data. If a unit root is present, appropriate transformations of the data are needed $(\log$ normal transformations are useful). The ADF tests the following hypothesis:

$\boldsymbol{H}_{\mathbf{0}}=$ the data exhibit non-stationarity and

$\boldsymbol{H}_{\mathbf{1}}=$ the data exhibit stationarity.

\section{Multicollinearity}

In the FF3FM, it is necessary to test whether high correlation exists among the explanatory variables. If high correlations exist it creates difficulty in distinguishing between individual variables effects, as both variables may be explaining the same thing. Multicollinearity may lead to spurious regressions, inflated $R^{2}$ values and inaccurate significance levels.

\section{Factor Analysis}

The first two moments of the SMB and HML factors are computed over the 2010-2015 period, as well as the 20102014 period. The omission of 2015 was carried through as a comparative procedure to illustrate the effects of market volatility on each factor.

\subsection{Portfolio Performance}

Jenson's Alpha $(\alpha)$

Jenson's $\alpha$ (Jensen, 1967), is a performance evaluation procedure which tests whether the intercept $(\alpha)$ of a regression is statistically significant. Positive $\alpha$ s imply outperformance of the market benchmark (Top 40 index), whilst negative $\alpha$ s imply underperformance. For each individual portfolio the hypothesis tested at the $5 \%$ level is:

$\boldsymbol{H}_{\mathbf{0}}$ : The intercept $(\alpha)$ of the regression model for the CAPM/FF3FM is not significant and

$\boldsymbol{H}_{\mathbf{1}}$ : The intercept $(\alpha)$ of the regression model for the CAPM/FF3FM is significant.

If $\alpha \mathrm{s}$ are found to be significant, it is indicative of the fact that the regression model omits or fails to capture other factors, which should be priced.

\section{Sharpe Ratio}

The Sharpe ratio is a simple risk-adjusted return measure (Sharpe, 1964). For each of the six portfolios the Sharpe ratio measure is calculated and compared, and indicates the level of excess return obtained for a specific volatility tolerance. The ratio is:

$$
S_{i}=\frac{\left(R_{i}-R_{f}\right)}{\sigma_{i}}
$$

where: $S_{i}=$ the Sharpe ratio for portfolio $i, R_{i}=$ average return on portfolio $i$ (annual), $R_{f}=$ average risk free rate (annual) and $\sigma_{i}=$ average standard deviation of portfolio $i$ (annual). 
The Sharpe ratio is considered under the caveat that potential abnormalities such as kurtosis and skewness may cause severe problems with the ratio (Brown, 2016).

\section{RESULTS AND DISCUSSION}

\section{Durbin Watson Test Result}

To ensure OLS regression was appropriate, auto-correlation amongst the portfolio residuals were tested, with the results indicated in Table 5, under the following hypotheses (at the 5\% level):

$\boldsymbol{H}_{\mathbf{0}}: \rho=0$ (there exists no auto- correlation present amongst the residuals)

$\boldsymbol{H}_{1}: \rho \neq 0$ (auto- correlation amongst the residuals exists).

In each case the Durbin Watson statistic exceeds the critical value (for $n=80, k=3$ ), the null hypotheses cannot be rejected, and it is concluded that no auto-correlation among residuals is present at the $5 \%$ level (DW stats $>1.72$ ).

Table 5. Summary output of the Durbin Watson (DW) test results for sample size $n=71$.

\begin{tabular}{|c|c|c|c|c|}
\hline $\begin{array}{l}\text { DW upper critical } \\
5 \% \text { for } n=\mathbf{8 0} \%\end{array}$ & DW statistic & Portfolio & Reject/Accept $\boldsymbol{H}_{0}$ & $n$ \\
\hline \multirow{6}{*}{1.72} & 1.983 & $\mathrm{~S} / \mathrm{L}$ & \multirow{6}{*}{ Reject } & \multirow{6}{*}{71} \\
\hline & 2.096 & $\mathrm{~S} / \mathrm{M}$ & & \\
\hline & 2.117 & $\mathrm{~S} / \mathrm{H}$ & & \\
\hline & 2.092 & $\mathrm{~B} / \mathrm{L}$ & & \\
\hline & 2.192 & $\mathrm{~B} / \mathrm{M}$ & & \\
\hline & 1.981 & $\mathrm{~B} / \mathrm{H}$ & & \\
\hline
\end{tabular}

Augmented Dickey Fuller Test Result

The stationarity of the time series data was tested using the Augmented Dickey Fuller test (Table 6). In each case, the null and alternate hypotheses tested are:

$\boldsymbol{H}_{\mathbf{0}}=$ the data exhibit non-stationarity and

$\boldsymbol{H}_{\mathbf{1}}=$ the data exhibit stationarity.

All portfolios except $\mathrm{S} / \mathrm{H}$ were significant at the $5 \%$ level, implying that the data for the other eight portfolios are significant. On closer inspection of the excess returns on the $\mathrm{S} / \mathrm{H}$ portfolio, they appeared to be two large values (in absolute terms) in the latter stages of 2015. These outliers were removed (mean replacement was introduced) and the test was re-run to yield a $p$-value of $3.29 \%$, implying that all nine portfolios became significant $(\alpha=0.05)$ after the adjustment process.

Table 6. Dickey Fuller test results for all nine portfolios. The lag order is assumed to be zero.

\begin{tabular}{l|c|c|c|c|}
\hline \multicolumn{1}{|c|}{ Portfolio } & DF test statistic & $\boldsymbol{p}$-value & Accept/Reject $\boldsymbol{H}_{\mathbf{0}}$ & Lag order \\
\hline $\mathrm{S} / \mathrm{L}$ & -3.58 & $4.23 \%$ & & \\
\hline $\mathrm{S} / \mathrm{M}$ & -3.78 & $2.53 \%$ & & \\
\hline $\mathrm{S} / \mathrm{H}$ & -3.69 & $3.29 \%$ & \multirow{2}{*}{ Reject } & \multirow{2}{*}{0} \\
\hline $\mathrm{B} / \mathrm{L}$ & -4.51 & $1.00 \%$ & & \\
\hline $\mathrm{B} / \mathrm{M}$ & -4.47 & $1.00 \%$ & & \\
\hline $\mathrm{B} / \mathrm{H}$ & -4.44 & $1.00 \%$ & & \\
\hline$R_{m}-R_{f}$ factor & -4.38 & $1.00 \%$ & & \\
\hline SMB factor & -3.69 & $3.27 \%$ & \\
\hline HML factor & -3.50 & $4.82 \%$ & \\
\hline
\end{tabular}

Copyright by author(s); $\underline{\mathrm{CC}-\mathrm{BY}}$ 


\subsection{Descriptive Statistics}

\section{Statistical Metrics and Portfolio Returns}

Table 8 summarises the first four moments of the data, spanning the entire sample period (2010-2015). The average excess return across the six portfolios during the sample period was $1.06 \%$ (13.5\% annually). This value is expected considering that the analysis was conducted over an expansionary phase of the South African macro-economic business cycle. On a portfolio-specific level, the $\mathrm{B} / \mathrm{L}$ portfolio obtained the highest average monthly return of $1.91 \%$, followed by S/L (1.63\%), S/M (1.62\%), B/M (0.90\%), B/H (0.42\%) and the lowest value attributable to S/H (-0.14\%) respectively. This finding again, stands in contrast to Fama and French $(1993 ; 1996)$ and the general historical observation, that on average, small and value stocks yield higher returns, relative to stocks which are classified as being both big and growth stocks.

Cumulative excess return data present in the table appear to show that if excess returns for the pair of three portfolio intersections are aggregated separately over the sample period, then the Small stock portfolios outperform the Large group portfolios by a small margin (128.4\% vs. $125.1 \%)$. The ranking order of returns on the basis of the Size and Value premiums (as evident in much of the literature in developed markets) does not hold true. Figure 2 shows the first moment of the six portfolios over the sample period.

Figure 2. Thee average monthly portfolio excess returns (2010-2015). 2014 shows a decline in excess returns across most portfolios. This is likely due to the large degree of volatility present in the market at the time.

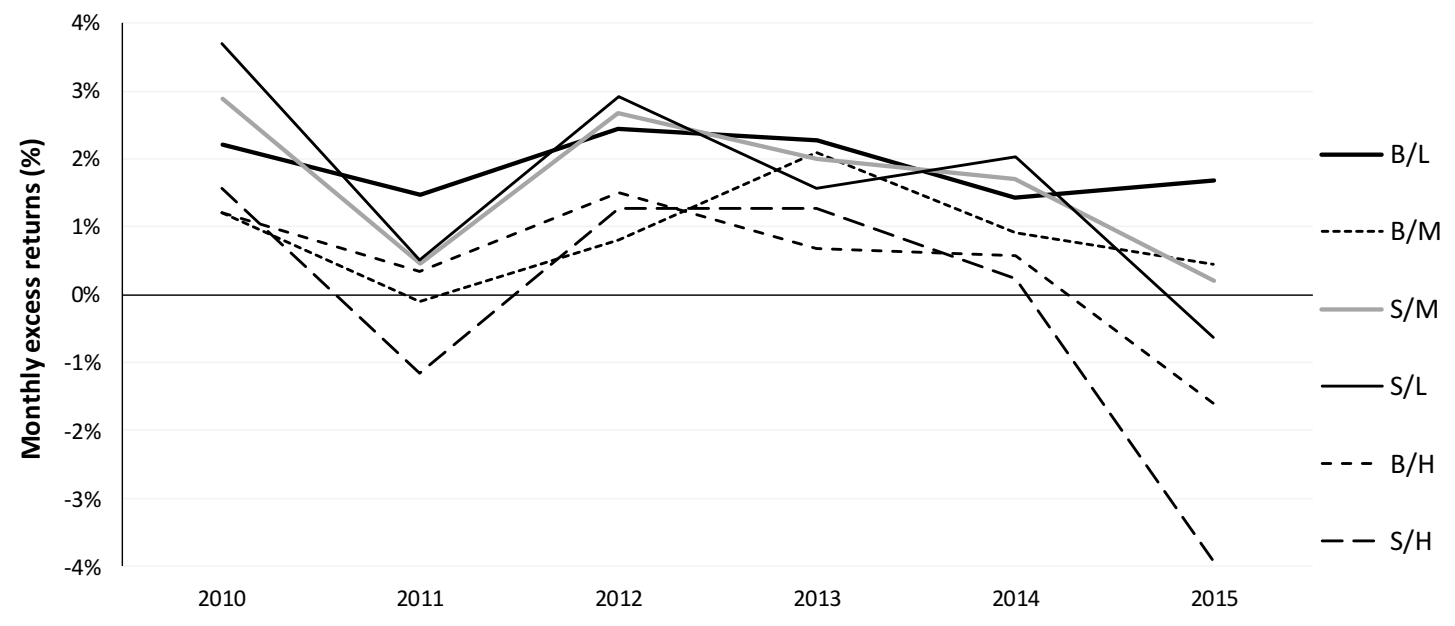

\section{Standard Deviation}

Higher standard deviations of the portfolios are associated with higher average excess returns. In general, the higher standard deviations of the portfolios are also characterised by higher a range of returns (i.e. the difference between the highest monthly excess return value and lowest). The exception to the above two observations is the $\mathrm{S} / \mathrm{H}$ portfolio a mining and minerals predominate portfolio, which returned on average, the highest monthly standard deviation $(4.73 \%)$ of all the portfolios over the sample period. This could be explained by the volatility associated with the mining sector, not only from the typical market sense but also from an investment sense. Foreign investment exhibits a strong positive relationship with economic growth, which in turn tends to increase general return levels and decrease volatility (Rahman, 2015). South Africa harbours some of the best mineral deposits in the world, yet it increasingly lacks an environment conducive to foreign investment. The Investment Attractiveness Index (IAI), computed by the Frasier Institute (2014), which measures mineral potential in conjunction with policy perceptions, ranked South Africa $66^{\text {th }}$. This is below countries such as the Democratic Republic of Congo and Ghana (Seccombe, 2016) - see Figure 3. 
Figure 3. Average monthly portfolio standard deviations (2010-2015), as in the case with the previous graph the latter half of 2014 is associated with high volatility, evident on the graph with spikes in portfolio standard deviation.

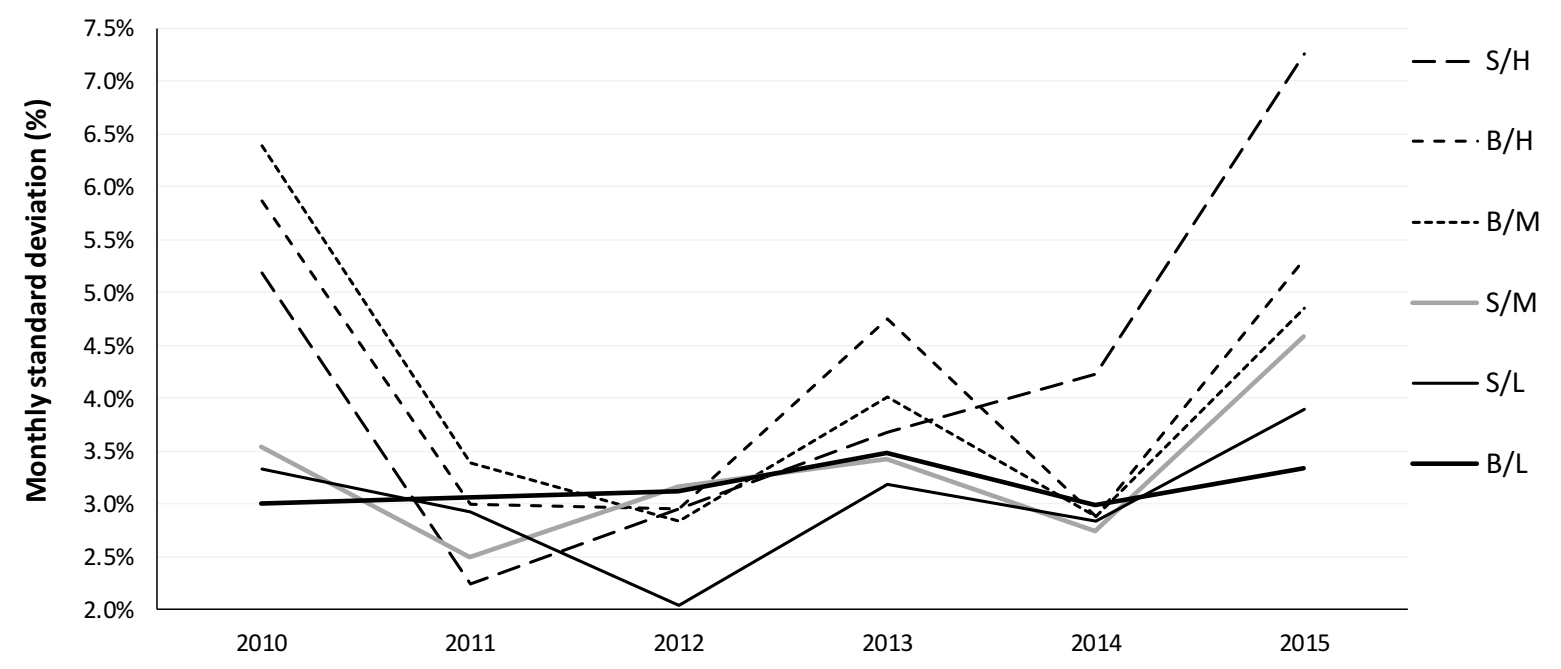

Skewness and Kurtosis

The returns are approximately normally distributed. Normal distributions exhibit skewness values close to zero (perfectly symmetrical) and a kurtosis of around 3. In both cases the data exhibit favourable results, with an average annual skewness $=-0.06$ and an average annual kurtosis $=2.74$. Although these results are indicative of a slightly platykurtic distribution, both values are considered in an acceptable range to conclude that data are approximately normally distributed.

Table 8. Descriptive portfolio statistics (2010-2015).

\begin{tabular}{l|c|c|c|c|c|c|c|c}
\hline \multicolumn{1}{c}{ Descriptive metrics } & S/L & S/M & S/H & B/L & B/M & B/H & Average \\
\hline Mean & $1.63 \%$ & $1.63 \%$ & $-0.14 \%$ & $1.91 \%$ & $0.90 \%$ & $0.43 \%$ & $1.06 \%$ \\
\hline Standard deviation & $3.77 \%$ & $3.50 \%$ & $4.73 \%$ & $3.33 \%$ & $4.12 \%$ & $4.16 \%$ & $3.94 \%$ \\
\hline Skewness & -0.15 & 0.010 & -0.17 & 0.003 & -0.001 & -0.05 & -0.06 \\
\hline Kurtosis & 2.79 & 2.71 & 2.79 & 2.77 & 2.68 & 2.77 & 2.75 \\
\hline High \% & $9.39 \%$ & $8.87 \%$ & $9.03 \%$ & $10.08 \%$ & $8.60 \%$ & $10.42 \%$ & $9.40 \%$ \\
\hline Low \% & $-8.87 \%$ & $-6.56 \%$ & $-14.15 \%$ & $-6.96 \%$ & $-7.84 \%$ & $-10.78 \%$ & $-9.19 \%$ \\
\hline Cumulative returns & $200.8 \%$ & $201.1 \%$ & $-16.8 \%$ & $269.6 \%$ & $78.5 \%$ & $27.2 \%$ & $126.7 \%$ \\
\hline
\end{tabular}

\subsection{Explanatory Variables: Risk Factors}

The arithmetic means over the period of 2010-2015 for the SMB and HML factors are $-0.04 \%$ and $-1.63 \%$ respectively. Although both negative, the SML is considerably lower than the HML. The HML's high negative value over 20102015 is a result of the low BE/ME portfolios outperforming the high BE/ME portfolios by a larger differential. This result contradicts the Fama and French (1993) observation that value stocks (i.e. high BE/ME ratios) should outperform growth stocks (with low BE/ME ratios). To illustrate the effect of volatility on factor performance, 2015 (a turbulent year in South Africa, particularly the latter half) has been omitted from the computation. Once 2015 data are removed, both the SMB $(0.28 \%)$ and HML $(-1.29 \%)$ increase. The HML becomes less negative and both factor standard deviations decrease by $\approx 11 \%$. The SMB becomes positive, implying that small firms outperform relatively larger ones. This is expected on the principal of expected return/risk trade off.

The effect on the market factor is less pronounced. The mean value increases from $0.46 \%$ for the $2010-2015$ periods to $0.57 \%$ when 2015 is omitted (2010-2015). This is indicative of higher growth rates prior to 2015, in the 
macroeconomy. This translates to higher returns on the overall market (as proxied by the top 40 market index), while the standard deviation remained approximately the same. Figure 4 provides the growth rates of the South African economy from 2013 to 2016.

Table 9. Factor summaries for both 2010-2015 and 2010-2014.

\begin{tabular}{|c|c|c|c|c|}
\hline & & Market Premium & SMB & HML \\
\hline \multirow{2}{*}{ 2010-2015 } & Mean & $0.466 \%$ & $-0.04 \%$ & $-1.63 \%$ \\
\hline & Standard Deviation & $3.853 \%$ & $2.342 \%$ & $3.486 \%$ \\
\hline \multirow{2}{*}{ 2010-2014 } & Mean & $0.570 \%$ & $0.285 \%$ & $-1.295 \%$ \\
\hline & Standard Deviation & $3.862 \%$ & $2.084 \%$ & $3.116 \%$ \\
\hline
\end{tabular}

Figure 4. South African growth rate, measured by GDP from Jul-13 to Jan-16.

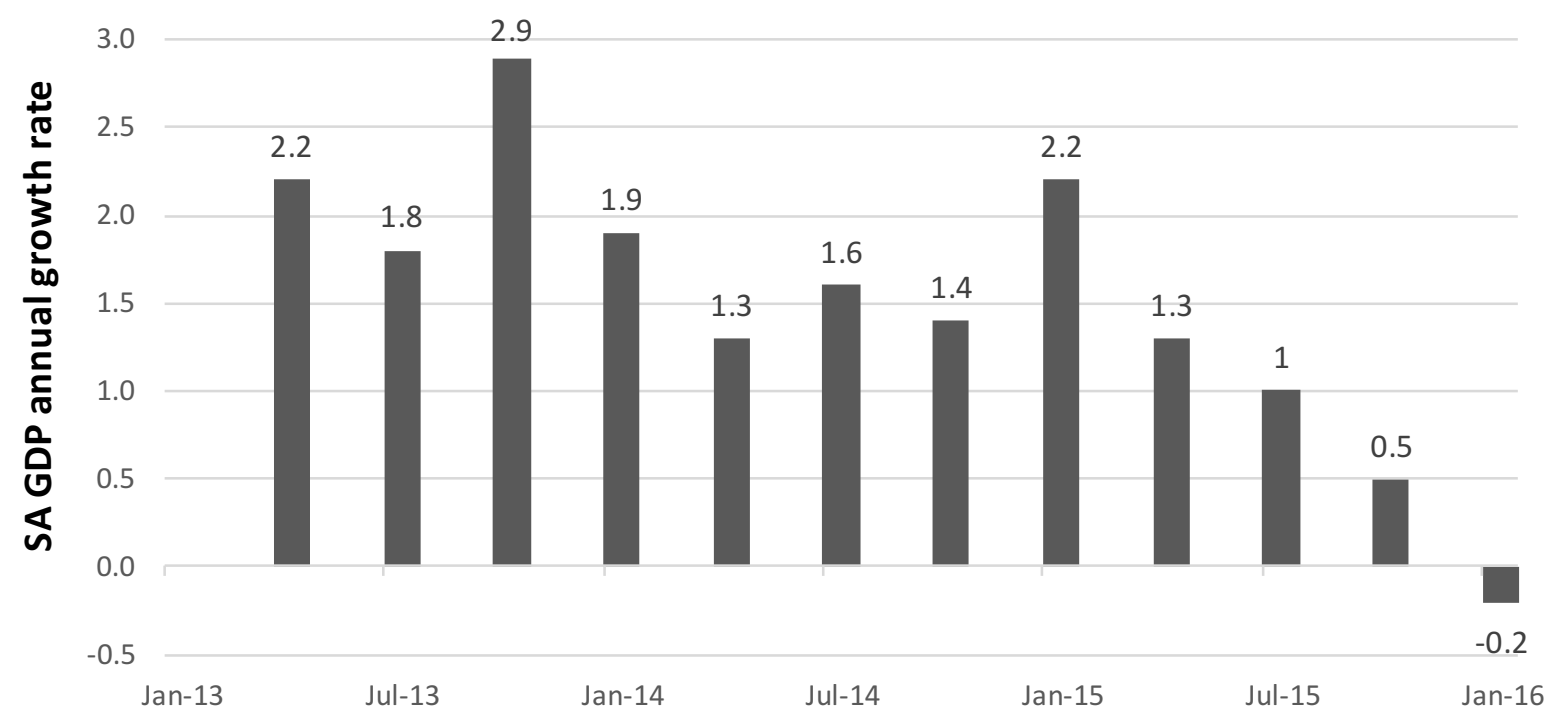

Source: (TradingEconomics, 2016)

\subsection{Factor Correlation Interpretation}

For the 2010-2015 period (Table 10), it is observable that a positive yet weak correlation exists between the HML $(0.065)$ and SMB (0.24) factor portfolios, and the excess market portfolio $\left(R_{m}-R_{f}\right)$ respectively. A possible reason for these low correlations may stem from the fact that most of the companies listed in the sample are Top 40 Index constituents, and represent multinational companies with well-diversified operations world-wide. Steinhoff International Holdings Limited, for example, is a parent company which manufactures and distributes household commodities and furniture based products throughout Sub-Saharan Africa and Europe (Steinhoff, 2015). Imperial Holdings Limited, a vehicle related import distribution retail, and rental company, as another example, operates in over 1200 locations and 31 countries, with operations spanning five continents (Imperial, 2016).

Many of the shares used in the data sample are listed in several other stock markets. These include exchanges such as the London Stock Exchange (LSE) and the New Stock Exchange (NYSE), and share returns are directly affected by market movements in these foreign markets, in addition to domestic movements, perhaps in many cases more so than the JSE.

Current (2016) South African regulations permit foreign domiciled companies to be treated as domestic based listings and the last decade has seen foreign exchange rules and tight equity holding regulations (for domestic investors) relaxed (Valery, 2015). While this may pose an important regulatory exchange shift in terms of enhancing the JSE as 
a more attractive listing destination, this hampers the ability of traditional asset pricing models to fully explain stock returns. This is observed when pricing the market factor as a proxy for the market, which then becomes harder to capture.

The positive yet weak correlation between HML and SMB (0.083) is expected, as most of the stocks in the sample represent the largest MEs stocks on the JSE, and many of companies across the portfolio intersections operate within in the same industry and are thus subject to similar forces. Moreover, because portfolios are rebalanced annually according to the relative benchmarks of BE/ME and ME, movements of stocks into different portfolios could serve as part of the explanation. For example: Old Mutual began as a company in the B/M portfolio in 2010 after which it transitioned to the $\mathrm{B} / \mathrm{H}$ portfolio. Initially, it would form part of the SMB calculation, yet after the transition it would be included in both the SMB and HML calculations.

Evidence of this weak correlation serves to rule out any potential issue of multicollinearity. Were the data found to be highly correlated, small changes in the data could result in erratic changes in coefficient estimates, and impair the predictive power of models used in the regression (Table 10).

Table 10. Summary of correlation matrix amongst factors 2010-2015 and 2010-2014.

\begin{tabular}{|c|c|c|c|c|}
\hline & & $\boldsymbol{R}_{\boldsymbol{m}}-\boldsymbol{R}_{\boldsymbol{f}}$ & SMB & HML \\
\hline \multirow{3}{*}{$2010-2015$} & $R_{m}-R_{f}$ & 1 & & \\
\hline & SMB & 0.243 & 1 & \\
\hline & HML & 0.065 & 0.083 & 1 \\
\hline \multirow{3}{*}{$2010-2014$} & $R_{m}-R_{f}$ & 1 & & \\
\hline & SMB & 0.247 & 1 & \\
\hline & HML & 0.099 & -0.241 & 1 \\
\hline
\end{tabular}

\subsection{CAPM Regression Results}

2015 was a tumultuous year for the South African market. Table 11 represents the CAPM regression of each portfolio using the market premium as the sole risk factor. The results suggest that the CAPM performs poorly in predicting the stock return variation as evidenced by low adjusted $R^{2}$ values which range from $3.1 \%$ to $6.2 \%$. All of the Small grouped stocks, namely S/L, S/M and S/H's market premiums are statistically insignificant at the $5 \%$ level, suggesting that while the CAPM performs unfavourably overall, it performs better for Big group stocks relative to Small group stocks. The negative $\beta$ s indicate the lack of co-movement between portfolios and market. This is not surprising: many of the company constituents are well diversified and multinational and are subject to international market movements: the Top 40 Index, as a market proxy, fails to explain stock returns.

When 2015 is removed from the analysis such that the regression spans the period from 2010-2014, all adjusted $R^{2}$ values increase (Table 12). Although these increases are slight $(0.93 \%$ to $2.52 \%)$, it renders the S/L portfolio statistically significant at the $5 \%$ level, where previously it was not. This increased performance is potentially s a result of the omission of the 2015 market volatility within South Africa, as well as shortening the forecast period, which in turn reduces the possibility of unbiased $\beta$ estimates. These results support the findings of Fama and French (1992), which argue that the CAPM fails to capture a significant portion of stock return variation.

Table 11. CAPM regressions 2010-2015.

\begin{tabular}{l|c|c|c|c}
\hline $\mathbf{2 0 1 0 - 2 0 1 5}$ & $\boldsymbol{\beta}$ & Adjusted $\boldsymbol{R}^{\mathbf{2}}$ & Standard error & $\boldsymbol{p}$-value B \\
\hline $\mathrm{S} / \mathrm{L}$ & -0.206 & 0.031 & 3.736 & 0.077 \\
\hline $\mathrm{S} / \mathrm{M}$ & -0.042 & -0.012 & 3.544 & 0.698 \\
\hline $\mathrm{S} / \mathrm{H}$ & -0.063 & -0.012 & 4.794 & 0.673 \\
\hline $\mathrm{B} / \mathrm{L}$ & -0.238 & 0.062 & 3.251 & 0.020 \\
\hline $\mathrm{B} / \mathrm{M}$ & -0.253 & 0.042 & 4.059 & 0.047 \\
\hline $\mathrm{B} / \mathrm{H}$ & -0.265 & 0.046 & 4.095 & 0.040 \\
\hline
\end{tabular}


Table 12. CAPM regressions 2010-2014.

\begin{tabular}{|c|c|c|c|c|}
\hline $2010-2014$ & $\beta$ & Adjusted $R^{2}$ & Standard error & $p$-value B \\
\hline $\mathrm{S} / \mathrm{L}$ & -0.245 & 0.056 & 3.450 & 0.040 \\
\hline $\mathrm{S} / \mathrm{M}$ & -0.094 & -0.005 & 3.287 & 0.400 \\
\hline $\mathrm{S} / \mathrm{H}$ & -0.058 & -0.014 & 3.764 & 0.647 \\
\hline $\mathrm{B} / \mathrm{L}$ & -0.248 & 0.068 & 3.213 & 0.026 \\
\hline $\mathrm{B} / \mathrm{M}$ & -0.272 & 0.052 & 3.967 & 0.046 \\
\hline $\mathrm{B} / \mathrm{H}$ & -0.275 & 0.060 & 3.763 & 0.034 \\
\hline
\end{tabular}

\subsection{The FF3FM Regression Results}

Initial Regression Results (2010-2015)

The result summary in Table 13, listed below, indicates that the FF3FM performs relatively weak. As a point of first reference, the adjusted $R^{2}$ values appear to fair quite unfavourably, ranging from $11.26 \%$ to $50 \%$ across the portfolios. In light of the market environment, this is not surprising.

For the coefficient estimates on the market factor, four of the six loadings are insignificant at the $5 \%$ level, with only $\mathrm{S} / \mathrm{L}$ and $\mathrm{B} / \mathrm{L}$ as exceptions. Again, the plausible explanation for this stems from the multi-national listings and company diversification discussed in the previous section. In view of the HML (Value) factor, four of the six portfolios are deemed significant at the $5 \%$ level, with the exception of the $\mathrm{S} / \mathrm{L}(p$-value $=43.1 \%)$ and $\mathrm{S} / \mathrm{M}(p$-value $=97.6 \%)$ portfolio. Looking at the portfolio constituents of the S/L and S/M portfolios respectively, it becomes apparent, that over the sampling period an average of $61 \%$ (ranging from $50 \%$ to $69 \%$ ) of the companies were outside the JSE Top 40.

The implication of this is twofold. First, it suggests, potentially, that using a book-to- market ratio and ME measure as risk proxies for firms below certain value "thresholds" is not appropriate. Portfolio constituents of the low and medium groups in studies conducted on developed markets are often superior in both sheer size and BE/ME ratio values to those of emerging markets.

Secondly, the risk characteristic profiles of Small grouped companies are likely to differ from that of Large grouped companies, which could explain the weak predictive power of the HML in this case. Some examples, among others could include: operating constraints, level of foreign market exposure, cost profiles and production constraints (economies of scale in production industries).

Controlling for size, it also found that the loadings on HML increases monotonically from the low to high BE/ME portfolios in both small and big groups, and is consistent with Fama and French (1995).

The results for the SMB (Size) factor indicate consistent significance of the coefficients at the $5 \%$ level $(\alpha=0.05)$ among all six portfolios, with $p$-values ranging between $0.11 \%$ and $2.49 \%$. Interestingly, all three big sized portfolios load negatively on SMB, while all three small sized portfolios have positive loadings. This is consistent with Fama French's (1995) "small firm effect" that smaller firms tend to outperform large ones, under the caveat that HML and the market premium is controlled for.

The adjusted $R^{2}$ values have increased, with increases in BE/ME and ME directly, confirming that the model performs better on larger based value stocks (high $\mathrm{BE} / \mathrm{ME}$ ratios). 
Table 13. Initial regression results 2010-2015.

\begin{tabular}{l|c|c|c|c|c|c|c}
\hline $\mathbf{2 0 1 0}-\mathbf{2 0 1 5}$ & $\boldsymbol{\beta}$ & $\mathbf{S}$ & $\mathbf{H}$ & Adjusted $\boldsymbol{R}^{\mathbf{2}}$ & $\boldsymbol{p}$-value B & $\boldsymbol{p}$-value S & $\boldsymbol{p}$-value H \\
\hline $\mathrm{S} / \mathrm{L}$ & -0.275 & 0.504 & -0.097 & $10.26 \%$ & 0.019 & 0.009 & 0.431 \\
\hline $\mathrm{S} / \mathrm{M}$ & -0.130 & 0.593 & 0.003 & $11.27 \%$ & 0.221 & 0.001 & 0.976 \\
\hline $\mathrm{S} / \mathrm{H}$ & -0.199 & 0.576 & 0.878 & $49.95 \%$ & 0.068 & 0.002 & 0.000 \\
\hline $\mathrm{B} / \mathrm{L}$ & -0.167 & -0.358 & -0.304 & $21.30 \%$ & 0.082 & 0.025 & 0.004 \\
\hline $\mathrm{B} / \mathrm{M}$ & -0.195 & -0.538 & 0.369 & $19.36 \%$ & 0.105 & 0.007 & 0.005 \\
\hline $\mathrm{B} / \mathrm{H}$ & -0.243 & -0.430 & 0.720 & $43.31 \%$ & 0.018 & 0.011 & 0.000 \\
\hline
\end{tabular}

\section{Removal of Insignificant Variables and Disjoint Tests}

Subsequent to the initial regression tests, backward elimination conducted at the $5 \%$ level $(\alpha=0.05)$ was carried out and the regressions were re-run (Table 14). The adjusted $R^{2}$ values fell slightly, ranging from $11 \%$ to $48 \%$, with the highest values attributable to the portfolios with high $\mathrm{BE} / \mathrm{ME}$ ratios $(\mathrm{S} / \mathrm{H}$ and $\mathrm{B} / \mathrm{H}$ respectively). The issue of the market premium insignificance from four of the six portfolios, is clearly indicative of the lack of an efficient market proxy, mentioned above, and possible solutions for this be dealt with in the recommendation section of the paper.

Table 14. Regression results subsequent to the removal of insignificant variables 2010-2015.

\begin{tabular}{l|c|c|c|c|c|c|c}
\hline $\mathbf{2 0 1 0}-\mathbf{2 0 1 5}$ & $\boldsymbol{\beta}$ & $\mathbf{S}$ & $\mathbf{H}$ & Adjusted $\boldsymbol{R}^{\mathbf{2}}$ & $\boldsymbol{p}$-value B & $\boldsymbol{p}$-value S & $\boldsymbol{p}$-value H \\
\hline $\mathrm{S} / \mathrm{L}$ & -0.279 & 0.494 & - & 0.108 & 0.017 & 0.010 & - \\
\hline $\mathrm{S} / \mathrm{M}$ & - & 0.541 & - & 0.119 & - & 0.002 & - \\
\hline $\mathrm{S} / \mathrm{H}$ & - & 0.498 & 0.868 & 0.481 & - & 0.006 & 0.000 \\
\hline $\mathrm{B} / \mathrm{L}$ & - & -0.424 & -0.313 & 0.189 & - & 0.008 & 0.003 \\
\hline $\mathrm{B} / \mathrm{M}$ & - & -0.615 & 0.359 & 0.173 & - & 0.002 & 0.007 \\
\hline $\mathrm{B} / \mathrm{H}$ & -0.243 & -0.430 & 0.720 & 0.433 & 0.018 & 0.011 & 0.000 \\
\hline
\end{tabular}

The loadings and significance of the remaining factors in each portfolio are dissimilar to the previous regression, indicating that although the model is weak in predictive prowess, it is fairly stable. The SMB factor is a significant predictor in all six of the portfolios, while the HML is significant in only four of the six. Which of these factors contributes more in explaining overall, expected stock returns? Two additional regressions were run to answer this question (Tables 15 and 16), considered in disjoint tests. The HML and market premium were considered together and the SMB and market premium. Adjusted $R^{2}$ values indicate that the HML factor (adjusted $R^{2}:-2.62 \%$ to $42.84 \%$ ) explains a much larger portion of the variation in expected stock returns than the SMB (adjusted $R^{2} 7.05 \%$ to $12.57 \%$ ). Moreover, the HML factor appears to be a more powerful predictor for firms with high BE/ME ratios, with adjusted $R^{2}$ values of $42.84 \%$ for the $\mathrm{S} / \mathrm{H}$ and $38.49 \%$ for the $\mathrm{B} / \mathrm{H}$ portfolios respectively. On a more general level, the result indicates that the $\mathrm{BE} / \mathrm{ME}$ ratio is a more powerful predictor than firm size, an important finding consistent with Fama French (1992).

Table 15. Regressions using SMB and the market premium (2010-2015).

\begin{tabular}{l|c|c|c|c|c}
\hline $\boldsymbol{R}_{\boldsymbol{m}}-\boldsymbol{R}_{\boldsymbol{f}}$ SMB & $\boldsymbol{\beta}$ & $\mathbf{S M B}$ & Adjusted $\boldsymbol{R}^{2}$ & $\boldsymbol{p}$ value B & $\boldsymbol{p}$ value S \\
\hline S/L & -0.279 & 0.494 & 0.108 & 0.0017 & 0.010 \\
\hline S/M & -0.130 & 0.593 & 0.126 & 0.217 & 0.001 \\
\hline S/H & -0.162 & 0.670 & 0.080 & 0.270 & 0.007 \\
\hline B/L & -0.180 & -0.390 & 0.121 & 0.076 & 0.020 \\
\hline B/M & -0.179 & -0.499 & 0.106 & 0.155 & 0.018 \\
\hline B/H & -0.212 & -0.353 & 0.071 & 0.103 & 0.099 \\
\hline
\end{tabular}


Table 16. Regressions using HML and the market premium (2010-2015).

\begin{tabular}{c|c|c|c|c|c}
\hline $\boldsymbol{R}_{\boldsymbol{m}}-\boldsymbol{R}_{\boldsymbol{f}}$ SMB & $\boldsymbol{\beta}$ & HML & Adjusted $\boldsymbol{R}^{\mathbf{2}}$ & $\boldsymbol{p}$ value B & $\boldsymbol{p}$ value H \\
\hline $\mathrm{S} / \mathrm{L}$ & -0.202 & -0.074 & $2.1 \%$ & 0.086 & 0.563 \\
\hline $\mathrm{S} / \mathrm{M}$ & -0.044 & 0.030 & $-2.6 \%$ & 0.689 & 0.804 \\
\hline $\mathrm{S} / \mathrm{H}$ & -0.115 & 0.904 & $42.8 \%$ & 0.303 & 0.000 \\
\hline $\mathrm{B} / \mathrm{L}$ & -0.219 & -0.321 & $16.4 \%$ & 0.024 & 0.003 \\
\hline $\mathrm{B} / \mathrm{M}$ & -0.273 & 0.344 & $11.5 \%$ & 0.027 & 0.012 \\
\hline $\mathrm{B} / \mathrm{H}$ & -0.305 & 0.700 & $38.5 \%$ & 0.004 & 0.000 \\
\hline
\end{tabular}

Omission of 2015 in the Regression (2010-2014)

To illustrate the effect of model robustness in terms of explanatory power during periods of volatility time series regressions were conducted throughout the sample period with the omission of 2015 (i.e. 2010-2014). Five of the six portfolios report adjusted $R^{2}$ that were higher, when 2015 was excluded, with the exception of the $\mathrm{S} / \mathrm{H}$ portfolio (a $23 \%$ decrease). When analysing the constituents, the $\mathrm{S} / \mathrm{H}$ portfolio is found to be comprised of two thirds mining companies and one third logistics established companies. 2014 proved to be a worse year for the mining sector (irrespective of the other macro-economic volatility) than 2015. 2014 yielded a 1.4\% reduction in overall mining production while a growth rate of 3.5\% was achieved in 2015 (Statistics South Africa, 2015). Mining strikes and reduced investor confidence further served as volatility amplifiers, which affected the predictive power of the factors on the $\mathrm{S} / \mathrm{H}$ portfolio.

\subsection{Comparison between the CAPM and the FF3FM}

The FF3FM outperforms the CAPM with respect to capturing variation in responses. The adjusted $R^{2}$ values for the initial regressions are significantly higher, amounting to differences as high as $49 \%$ within the individual portfolios.

\subsection{Portfolio performance evaluation}

Jensen's Alpha

For the regressions spanning 2010-2015 (see Table 17):

$\boldsymbol{H}_{\mathbf{0}}$ : The intercept $(\alpha)$ of the regression model for the CAPM/FF3FM is not significant and

$\boldsymbol{H}_{\mathbf{1}}$ : The intercept $(\alpha)$ of the regression model for the CAPM/FF3FM is significant.

All six of the $\alpha$ values for the FF3FM portfolios are positive and statistically significant at the 5\% level, implying that the expected return is underestimated and the alternative Hypothesis (H1) can be accepted. This underpins the fact that the model fails to capture a portion of systematic risk that should be proxied for by other factors (e.g. liquidity). In the case of the CAPM, five of six of the portfolios are significant at the $5 \%$ level, S/H being highly insignificant. These results should be treated with caution, however, as the $\alpha$ s should be considered in conjunction with $R^{2}$ model values.

Table 17. $\alpha$ (regression intercept) summary for CAPM and FF3FM over 2010-2015.

\begin{tabular}{l|c|c|c|c}
\hline Portfolio & FF3FM $\boldsymbol{\alpha}$ & $\boldsymbol{p}$-value & CAPM $\boldsymbol{\alpha}$ & $\boldsymbol{p}$-value \\
\hline $\mathrm{S} / \mathrm{L}$ & 0.016 & $0.11 \%$ & 0.017 & $0.024 \%$ \\
\hline $\mathrm{S} / \mathrm{M}$ & 0.017 & $0.02 \%$ & 0.016 & $0.023 \%$ \\
\hline $\mathrm{S} / \mathrm{H}$ & 0.014 & $0.24 \%$ & -0.001 & $18.958 \%$ \\
\hline $\mathrm{B} / \mathrm{L}$ & 0.015 & $0.04 \%$ & 0.020 & $0.000 \%$ \\
\hline $\mathrm{B} / \mathrm{M}$ & 0.016 & $0.21 \%$ & 0.010 & $3.892 \%$ \\
\hline $\mathrm{B} / \mathrm{H}$ & 0.017 & $0.01 \%$ & 0.006 & $4.862 \%$ \\
\hline
\end{tabular}




\section{Sharpe Ratio}

From a risk-adjusted performance basis, on average, the Big sized portfolio group slightly outperformed the Small sized group (1.18 vs. 1.16) - see Figure 5. B/L performed the best (2.32), whilst $\mathrm{S} / \mathrm{H}$ performed the worst (-0.22). In the big portfolios the Sharpe ratio decreased monotonically as the book to market value became higher. This may be an important consideration for future studies.

Figure 5. The Sharpe Ratio value for each portfolio over the sample period (2010-2015).

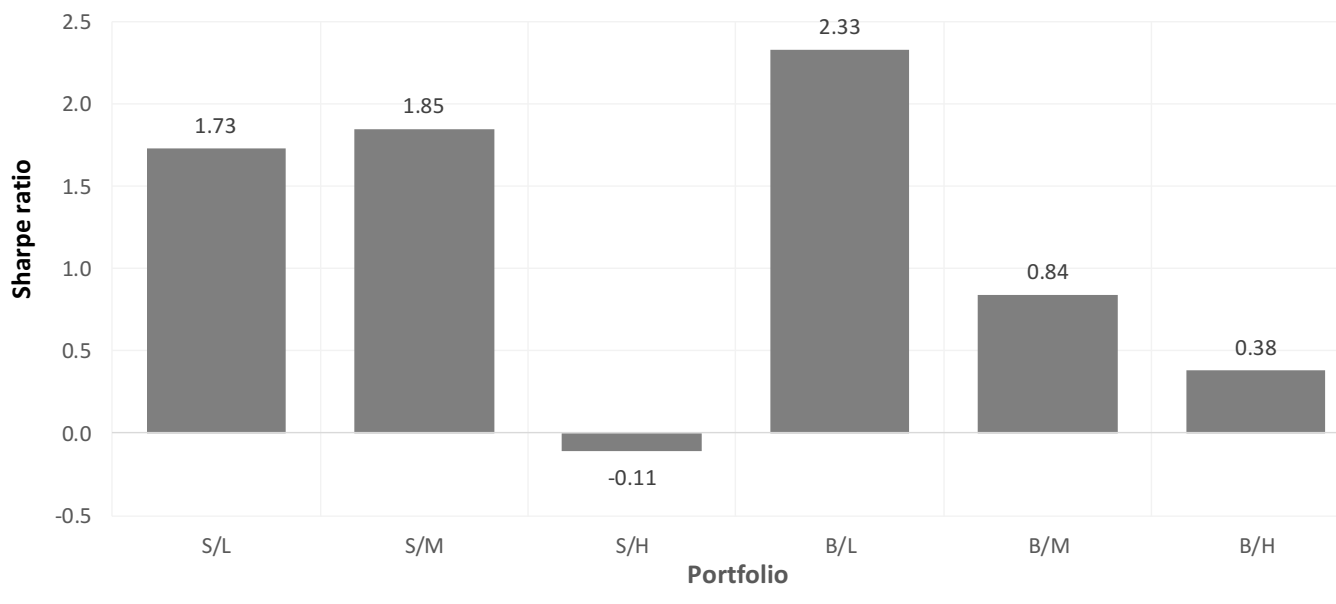

\section{CONCLUSION}

Using an adapted approach of Fama and French $(1993,1995)$ a final sample of 46 JSE stocks, spanning a period from 2010 to 2015 , were sorted and stratified, by size and book-to-market values - into a $3 \times 2$ assortment of portfolios. The portfolios were re-balanced annually on a relative value basis and used in the evaluation of the multiple regressions on both the CAPM and the FF3FM. Results indicate that both models are limited in their explanatory ability, however, the FF3FM (adjusted $R^{2}$ range: $11.32 \%$ to $50.00 \%$ ) clearly outperforms the CAPM (adjusted $R^{2}$ range: $3.14 \%$ to $6.25 \%$ ) in all portfolios. A common problem amongst both models, points to the lack of a sufficient market proxy, and is one of the key reasons for the low performance. Other reasons for the poor performance include the liquidity issue and inherent volatility present in South Africa during the sample period.

On a risk-adjusted performance basis, the portfolios are non-monotonic in nature, with $\mathrm{B} / \mathrm{L}$ and $\mathrm{S} / \mathrm{H}$ performing the best and worst respectively. This stands in contrast to Fama and French (1993), who observe a monotonic relationship of small firms outperforming big firms. The results in this respect are inconclusive, as the data sample limitations in both size and period cannot be discounted. Larger and more comprehensive studies should be applied to ascertain this.

Two disjoint-paired tests of both the SMB and Market factors and HML and Market factors, indicated that although both factors were significant, the HML factor, explained a much larger proportion of the variation in excess stock returns, as opposed to the SMB factor. This implies that it is a stronger predictor when applied to the JSE, ${ }^{14}$ supporting Fama and French's (1995) Small Firm Effect.

\footnotetext{
${ }^{14}$ This was the case in 4 of the 6 portfolios - with the exception of S/L and S/M. 


\section{RECOMMENDATIONS FOR FURTHER STUDY}

\subsection{Time-Series Regression: Time Horizon and Sample Size}

Often one of the most salient limitations associated with time-series regression is the quality of data sample. The period may be too short to fully capture the relationships between variables, and the sample may not be fully representative and/or non-synchronous trading may be evident (Basiewicz \& Auret, 2010). The explanatory variables span only a six-year period $(2010-2015)$, whereas Fama and French $(1993 ; 1996)$ include several decades of data. The implication of this is that the possibility of noise and bias to estimates, as a result of these ideas, cannot easily be refuted. A possible solution would be to include a sample spanning a longer time horizon, as well as including more companies.

\subsubsection{Inclusion of Unpriced Factors}

Perhaps the most obvious procedure would be to look at other risk factors which may better capture risk characteristics of asset behaviour in the South African market. A key issue identified in the context of South Africa was liquidity. Thus, a priced liquidity factor could be a significant additive to the regression model. Another finding among emerging markets is the historical volatility of loading estimations, due to time-varying components. Adjusting the model for the time-varying $\beta$ s could help.

The extension of the FF3FM to the FF5FM (Fama \& French, 2014), which includes Profitability and Investment, or momentum (Carhart, 1997) may better proxy systematic risk for emerging markets.

\subsubsection{Portfolio Partitioning and Factor Computation}

A key component influencing the portfolios descriptive metrics is the constituents in the portfolio. While the method employed in this study sought to partition based on overall ME and BE/ME value, an interesting adjustment to further study could involve the partitioning of portfolios based instead on industry sectors. This may result in better explain the cross section variation in returns, but must be considered in light of the models "threshold effect". SMB and HML factors could also be constructed on an industry basis, which would also then highlight the effects across industries better.

\subsubsection{Market Proxy}

Previous sections make extensive mention of the lack of explanatory power provided for the market proxy. A way around this issue could be to use industry based indices as the market benchmark for respective share/portfolio predictions. This would likely add significant power in the explained variation in the response, for example: A mining index could be used in the prediction of mineral-based companies or a financial index could be used in the prediction of financial assets. This is important, as different sectors are likely proxied by different risks - especially in emerging markets where volatility is higher than developed markets. A more general approach could involve a market index to proxy for small, medium and large market caps, when estimating different sized portfolios.

\subsubsection{Reduction in Bias and Accuracy of Estimation}

Following Dimson (1979) and Basiewicz (2010) - the latter of which appears to be the most comprehensive FF3FM study on the JSE - note that the largest problem with thin trading, is the bias in computed $\beta \mathrm{s}$, and thus, regression results. A lag period for factor $\beta$ s could be introduced.

\subsubsection{Dummy Variables and Interaction}

Different market sectors exhibit differing degrees of volatility. A potential model extension could also include a series of indicator variables (such that the recording process accounts for each binary prediction level represented by each 
JSE sector), which may improve the asset pricing models statistical accuracy. Further studies could also test for statistical interactions between factors.

\section{Alternative Techniques}

One of the underlying assumptions underpinning multiple linear regression is that the model follows a linearrelationship. Do current models indeed follow a linear relationship? Following the work of Koenker (2005) and Allen, Kumar-Singh and Powell, (2009), further tests for factor linearity, and as a way to tackle some of the issues discussed associated with time-series, with respect to the response, could be tested using the method of quantile regression. ${ }^{15}$ If non-linearity is found, data transformation could be applied to the series. Other helpful methods include Principal Component and Factor Analysis.

\section{AUTHOR BIOGRAPHIES}

Adam Karp, Postgraduate student, Department of Risk Management, North West University, Potchefstroom Campus, South Africa

Gary van Vuuren, Extraordinary professor, Department of Risk Management, North West University, Potchefstroom Campus, South Africa

\section{REFERENCES}

Allen, D. E., Kumar-Singh, A. \& Powell, R. J., 2009. Asset Pricing, the Fama-French Factor Model and the Implications of Quantile Regression Analysis. Sydney, Financial Research Network, 1-46.

Anon., 2009-2015. Current Market Rates. [Online] Available at: http://www.resbank.co.za/Research/Rates/Pages/CurrentMarketRates.aspx [Accessed 28 May 2016].

Anon., 2013. JSE Overview. [Online] Available at: https://www.jse.co.za/about/history-company-overview [Accessed 4 July 2016].

Anon., 2015. Mining: winners and losers 2015. [Online] Available at: http://www.statssa.gov.za/?p=6247 [Accessed 6th July $2016]$.

Auret, C. \& Sinclaire, R., 2006. Book-to-market ratio and returns on the JSE. Investment Analysts Journal, 35(63), pp. 31-38.

Banz, R. W., 1981. The relationship between return and market value of common stocks. Journal of Financial Economics, 9(1), $3-18$.

Bartholdy, J. \& Peare, P., 2005. Estimation of expected return: CAPM vs. Fama and French. International Review of Financial Analysis, 14(4), 407-427.

Basiewicz, P. \& Auret, C., 2010. Feasibility of the Fama and French three factor model in explaining returns on the JSE. Investment Analysts Journal, 39(71), 13-25.

Basu, S., 1977. Investment Performance of Common Stocks in Relation to Their Price-Earnings ratios. The Journal of Finance, 32(3), 663-682.

Basu, S., 1983. The Relationship Between Earnings' Yield, Market Value and Return For NYSE Common Stocks. Journal of Financial Economics, 12(1), 129-156.

Bernoulli, D. (1738). Specimen theoriae novae de mensura sortis (Exposition of a new theory on the measurement of risk). Comentarii Acad. Scient. Petropolis (translated in Econometrica), 5(22), 23-36.

Black, F., 1972. Capital Market Equilibrium with Restricted Borrowing. The Journal of Buisness, 45(3), 445-455.

Bodie, Z., Kane, A. \& Marcus, A., 2008. Investments by Bodie, Kane and Marcus 6th International Softcover Edition. 6th ed. London: McGraw-Hill Education.

Brown, S., 2016. Measures of Shape: Skewness and Kurtosis. [Online] Available at: http://brownmath.com/stat/shape.htm Accessed 2 August 2016].

Carhart, M. M., 1997. On Persistence in Mutual Fund Performance. Journal of Finance, 52(1), 57-82.

Chen, N.-F., Roll, R. \& Ross, S. A., 1986. Economic Forces and the Stock Market. The Journal of Business, 59(3), $383-403$.

Daniel, K. \& Titman, S., 1997. Evidence on the Characteristics of Cross Sectional Variation in Stock Returns. The Journal of Finance, 52(1), 1-33.

Davis, J. L., 1994. The Cross-Section of Realized Stock Returns: The Pre-COMPUSTAT Evidence. The Journal of Finance, ${ }^{15}$ An advantage of quantile regression, relative to the ordinary least squares regression, is that the quantile regression estimates are more robust
against outliers in the response measurements.

Copyright by author(s); $\underline{\mathrm{CC}-\mathrm{BY}}$ 
49(5), 1579-1593.

Dimson, E., 1979. Risk measurement when shares are subject to infrequent trading. Journal of Financial Economics, 7(2), pp. 197-226.

Djajadikerta, H. \& Nartea, G., 2005. The Size and Book-to-Market Effects and the Fama-French Three-Factor Model in Small Markets: Preliminary Findings from New Zealand. s.1.:School of Business, Edith Cowan University.

Drew, M. E., Naughton, T. \& Veeraraghavan, M., 2004. Is idiosyncratic volatility priced?. International Review of Financial Analysis, 13(1), 349-366.

Drew, M. E. \& Veeraraghavan, M., 2001. Explaining the Cross-Section of Stock Returns in the Asian Region. International Quarterly Journal of Finance, Volume 1, 205-221.

Faff, R., 2001. An Examination of the Fama and French Three-Factor Model Using Commercially Available Factors. Australian Journal of Management, 26(1), 1-17.

Fama, E. \& French, K., 1992. The Cross-Section of Expected Stock Returns. The Journal of Finance, XLVII(2), 1-40.

Fama, E. \& French, K., 1993. Common risk factors in the returns on. Joural of Financial Economics, 33(1), 3-56.

Fama, E. \& French, K., 1995. Size and Book-to-Market Factors in Earnings and Returns. The Journal of Finance, 1(1), $131-155$.

Fama, E. \& French, K., 1996. Multifactor Explanations of Asset Pricing Anomolies. Journal of Finance, 51(1), 55-84.

Fama, E. \& French, K., 1998. Value versus Growth: The International Evidence. The Journal of Finance, 53(6), $1975-1999$.

Fama, E., French, K. \& Davies, J. L., 2000. Characteristics, Covariances, and Average Returns: 1929 to 1997. The Journal of Finance, 55(1), 389-406.

Fama, E. French, K, 2004. The Capital Asset Pricing Model: Theory. Journal of Economic Perspectives, 18(3), 25-46.

Fama, E. \& French, K., 2014. A five-factor asset pricing model. Journal of Financial Economics. 116(1), 1-22.

Frasier Institute, 2014. The Investment Attractiveness Index. [Online] Available at: https://www.fraserinstitute.org/research, [Accessed 22 July 2016].

Gabrielsen, A., Kirchner, A., Liu, Z. \& Zagaglia, P., 2012. Forecasting Value-at-Risk with Time-Varying Variance, Skewness and Kurtosis in an Exponential Weighted Moving Average Framework. Annals of Financial Economics, 10(01), 1-29.

Gaunt, C., 2004. Size and book to market effects and the Fama French three factor asset pricing model: evidence from the Australian stockmarket. The Journal of Accounting and Finance, 44(1), 27-44.

Gregory, A. \& Michou, M., 2009. Industry Cost of Equity Capital: UK Evidence. Journal of Business Finance and Accounting (JBFA), 36(5-6), 679-704.

Griffin, J. M., 2002. Are the Fama and French Factors Global or Country Specific?. The Review of Financial Studies, 15(3), 783803.

H.Markowitz, 1959. Portfolio Selection: Efficent Diversification of Investments. Cowles Foundation for Research in Economics, $12(3), 12-100$.

Hearn, B. \& Piesse, J., 2013. Firm level governance and institutional determinants of liquidity: Evidence from Sub Saharan Africa. International Review of Financial Analysis, 28(1), 93-111.

Imperial, 2016. At a glance. [Online] Available at: http://www.imperial.co.za/abt-glance.php [Accessed 10 July 2016].

Jensen, M. C., 1967. The Performance of Mutual Funds in the Period 1945-1964. Journal of Finance, 23(2), 389-416.

Kampman, T., 2011. Explaining Stock Returns: the CAPM, Fama-French Three Factor Model and Carhart's Four Factor Model, s.l.: Tilburg University.

Kassimatis, K., 2008. Size, Book to Market and Momentum Effects in the Australian Stock Market. Australian Journal of Management, 33(1), 145-168.

Koenker, R., 2005. Quantile Regression. 1st ed. Cambridge: Cambridge Universtiy Press.

Lakonishok, J., Shleifer, A. \& Vishny, R. W., 1994. Contrarian Investment, Extrapolation, and Risk. The Journal of Finance, 49(5), 1541-1578.

Lakonishok, L. K., 1991. Fundamentals and Stock Returns in Japan. The Journal of Finance, 46(5), 1739-1764 .

La Porta, R., 1996. Expectations and the Cross Section of Stock Returns. Journal of Finance, 51(3), 1715-1742.

Lam, K. S., 2002. The relationship between size, book-to-market equity ratio, earnings-price ratio, and return for the Hong Kong stock market. Global Finance Journal, 13(2).

Litner, J., 1965. The Valuation of Risk Assets and the Slectionof Risky Investments in Stock Portfolios and Capital Budgets. The Review of Economics and Statistics, 47(1), 13-37.

Lockwood, L., Rodriguez, M., Goldreyer, E. \& Barry, C. B., 2002. Robustness of size and value effects in emerging equity markets, 1985-2000. Emerging Markets Review, 3(1), 1-30.

Markowitz, H., 1952. Portfolio Selection. The Journal of Finance, 7(1), pp. 77-91.

Mossin, J., 1966. Equilibrium in a Capital Asset Market. Econometrica, 34(4), 768-783.

Mullins, D. W., 1982. Does the Capital Asset Pricing Model Work?. [Online] Available at: https://hbr.org/1982/01/does-thecapital-asset-pricing-model-work [Accessed 2 July 2016].

Pasaribu, R. B., 2009. Stock Portfolio with Fama-French Model in Indonesian Stock Exchange. Journal of Accounting \& Business, 9(1), 1-12.

Porta, R. L., 1996. Expectations and the Cross-Section of Stock Returns. The Journal of Finance, 51(5), 1715-1742.

Rahman, A., 2015. Impact of Foreign Direct Investment on Economic Growth: Empirical. International Journal of Economics 
and Finance, 7(2), 1-8.

Reid, K., Rosenberg, B., Reid, K. \& Lanstein, R., 1985. Persuasive evidence of market inefficiency. The Journal of Portfolio Management, 11(3), 9-16.

Roll, R., 1977. A CRITIQUE OF THE ASSET PRICING THEORY'S TESTS - Part I: On Past and Potential Testability of the Theory*. Journal of Financial Economics , 4(1), 129-176.

Ross, S. A., 1976. The Arbitrage Theory of Capital Asset Pricing. Journel of Economic Theory, 13(1), 341-360.

SARB, 2016. Current market rates. [Online] Available at: http://www.resbank.co.za/Research/Rates/Pages/CurrentMarketRates.aspx [Accessed 12 June 2016]. sdf, n.d.

Seccombe, A., 2016. SA ranked 66th on attractiveness index for mining. [Online] Available at: http://www.bdlive.co.za/business/mining/2016/03/02/sa-ranked-66th-on-attractiveness-index-for-mining [Accessed 25 July 2016].

Sharpe, W. F., 1964. Capital Asset Prices: A Theory of Market Equilibrium under Conditions of Risk. The Journal of Finance, $19,(3), 425-442$.

Silva, A. C. D., 2006. Modeling and Estimating a Higher Systematic Co-Moment Asset Pricing Model in the Brazilian Stock Market. Latin American Business Review, 6(4), 85-101 .

Statistics-SouthAfrica, 2016. Economic Growth. [Online] Available at: http://www.statssa.gov.za/?page_id=735\&id=1 [Accessed 14 July 2016].

Steinhoff, 2015. Steinhoff Integrated Report Summary. [Online] Available at: http://www.steinhoffinternational.com/downloads/2016/Steinhoff\%20IR\%202015_Web_.pdf [Accessed 10 July 2016].

Tony-Okeke, U., 2015. Multi-Factor Asset Pricing Model in the South African Stock Market. Coventry: Coventry University Business School.

TradingEconomics, 2016. South Africa GDP Annual Growth Rate. [Online] Available at: http://www.tradingeconomics.com/south-africa/gdp-growth-annual [Accessed 14 July 2016].

Treynor, J. L., 1961. Market Value, Time, and Risk. Independent, 1(2), 1-46.

Valery, G., 2015. Estimating the Stocks Returns of the South African's FTSE/JSE TOP 40 Index, using the Fama French ThreeFactor Model and. Kaohsiung: National Sun Yat-sen University .

Van Rensburg, P. \& Robertson, M., 2003. Size, price-to-earnings and beta on the JSE Securities Exchange. Investment Analysts Journal, 32(58), 7-16. 


\section{NOTES}

